\title{
SIKAP ETIS HAMBA TUHAN TERHADAP KOLEGIALITAS \\ DALAM PELAYANAN.
}

Riky Handoko Sitindaon

\begin{abstract}
BAB I
PENDAHULUAN

Manusia diciptakan bukan untuk hidup sendiri melainkan dapat bersosialisasi dengan sesamanya. Sebab dalam kebersamaan ada kekuatan yang tidak kita miliki saat kita melakukan segala sesuatu sendiri. Hal ini tentunya berkaitan dengan pola kehidupan manusia yang selalu berinteraksi dan berkomunikasi dengan manusia lain. Membangun ikatan-ikatan sosial merupakan kebutuhan dasar dalam mencapai kebutuhan bersama oleh karena itulah dibutuhkan kerjasama yang didorang oleh rasa saling membutuhkan. Maka dengan demikian setiap pelayan Tuhan harus bekerjasama dan sehati untuk memberitakan visi kerajaan Allah.

Masalah kolegialitas menyangkut hubungan antar pendeta, baik yang sama-sama melayani dalam satu jemaat, maupun dalam lingkup yang lebih luas, seperti klasis, sinode wilayah dan sinode, bahkan di antara gereja-gereja yang berbeda denominasi di wilayah yang sama. Hubungan antara pendeta jemaat dengan pendeta emeritus, pendeta tugas khusus, dan pendeta pendahulu juga termasuk dalam konsep kolegialitas. Dalam konteks yang lebih luas, konsep kolegialitas seharusnya mencakup juga hubungan antara pendeta dengan pemimpin-pemimpin gerejawi yang lain, baik yang berjabatan resmi seperti penatua dan diaken, maupun pemimpin-pemimpin informal yang pada kenyataannya memiliki pengaruh dalam jemaat. Tetapi fokus makalah ini akan dibatasi hanya pada hubungan antar pendeta.

Di dalam pelayanan istilah kolegialitas ini bukanlah istilah yang sangat asing karena para hamba Tuhan pun memerlukan kolegialitas dalam melayani Tuhan. Dalam satu gereja misalnya pasti selalu ada team yang dibentuk untuk membangun iman dan semangat melayani Tuhan, baik itu dari kalangan teologia maupun dari kalangan orang awam dalam kemajelisan. Bahkan di beberapa gereja pasti ada pendeta atau hamba Tuhan yang sudah purna tugas atau emeritus, atau bahkan mantan gembala jemaat dan seharusnya merekalah yang menjadi kolegialitas seorang pelayan atau gembala jemaat dalam melayani Tuhan. Bahkan mungkin diberikan tanggung jawab dalam pelayanan bersama di dalam gereja. Yang menjadi masalah adalah ada banyak hamba-hamba Tuhan tidak ingin dibantu oleh pelayan
\end{abstract}


lain, dan merasa dapat melayani sendiri tanpa bantuan orang lain atau "single fighter". Namun, ada masalah personal yang akan timbul disaat seorang gembala atau pelayan yang jemaatnya adalah mantan gembala jemaat dalam gereja tersebut dan jemaat lebih intens dilayani pribadi oleh gembala yang sudah melayani di gereja tersebut, sharing, ingin di doakan, ingin dukunjungi dan lainnya. Sedangkan gembala jemaat di gereja tersebut merasa tersaingi dan menganggap gembala lama tersebut merebut hati jemaatnya, timbul iri hati dan kecemburuan dalam diri gembala tersebut.

Dari kasus seperti inilah diperlukan etika pelayanan terhadap kolegialitas para hamba Tuhan, agar yang terjadi bukan malah bersaing melainkan bekerja sama dalam mengembangkan dan menumbuhkan iman jemaat. Jika kolegialitas dalam pelayanan tidak ada etika maka yang terjadi adalah jemaat memiliki dualisme pemimpin, sehingga tidak gampang memang menerima keberadaan hamba Tuhan lain dalam pelayanan, akan ada banyak perbedaan dalam tindakan dan pemikiran terhadap cara dan tujuan dalam melayani. Maka itulah kegunaan dari etika pelayanan terhadap kolegialitas bagi hamba Tuhan agar dapat menemukan tujuan bersama dalam melayani jemaat Tuhan. Bukan hanya di dalam gereja saja melainkan dalam yayasan bahkan dalam pelayanan team lainnya yang harus memiliki jumlah yang tidak bisa satu dalam sebuah wadah pelayanan dan memerlukan kolegialitas sesama pelayan yang mampu mencapai tujuan bersama untuk kemuliaan Tuhan. Kerena tidak ada yang dapat melayani sendiri tanpa bantuan orang lain, maka dalam hal ini kolegialitas menjadi perlu karena untuk mencapai tujuan yang besar membutuhkan kerjasama yang baik. Oleh karena itu makalah ini dapat menolong para hamba Tuhan agar dapat menyikapi secara etis kristen terhadap kolegialitas sesama pelayan dalam melayani Tuhan.

\section{BAB II}

\section{DEFINISI ISTILAH}

Sebelum pembahasan lebih jauh tentang sikap etis hamab Tuhan terhadap kolegialitas dalam pelayanan ada baiknya telebih dahulu penulis memaparkan definisi istilah sebagai berikut.

\section{Etika}

Secara umum istilah ini bukanlah istilah yang asing bagi kalangan orang banyak. Menurut Kamus Bahasa Indonesia Kontemporer etika adalah IImu pengetahuan tentang moral atau peraturan tentang kelakuan yang benar dan salah. ${ }^{1}$ Istilah "etika atau ethics

\footnotetext{
${ }^{1}$ Peter Salim,Kamus Bahasa Indonesia Kontemporer, $(-),$,
} 
(Inggris) yang dikonstruksikan dalam bentuk singular berasal dari kata ethique yang pengetiannya ialah "studi moral; atau suatu sistem standar moral dari agama, dsb." Atau, studi tentang standard dari tindakan yang patut dan penetapan sikap moral; atau pembahasan tentang studi moral. Kata etika, dalam istilah Latin adalah ethica, dan istilah Yunani ethike. Ada dua bentuk istilah etika yang diangkat dari kata Yunani ethike, yaitu ethos atau ta ethika dan 'ethos atau ta 'ethika. Istilah ethos artinya., biasa, kebiasaan, adat (habit, custom, lihat: Lukas 22:39; Yohanes 19:40; Kisah Para Rasul 16:21; 25:16; Ibrani 10:25). Arti lain dari istilah ethos ini yang dirujuk secara sempit ialah "adat yang tertentu, atau peraturan atau norma" (Banding: Lukas 1:9; 2:42; Kisah para Rasul 6:14; 15:1; 21:1; 26:3; 28:17). Sedangkan, istilah 'ethos, memiliki dua arti dasar, yaitu: tempat tinggal yang biasa (home, abode); dan kebiasaan, atau adat (Banding: I Korintus 15:33). Tekanan khusus dari kata 'ethos ini "lebih berarti kesusilaan, perasaan batin, atau kecenderungan hati dengan mana seseorang melakukan suatu perbuatan". Istilah Etika juga memiliki arti, Nilai (Kultur). ${ }^{2}$

J.A.B Jingenel merumuskan definisi etika yang adalah ajaran tentang yang baik dan buruk dalam pikiran, perkataan, dan perbuatan manusia dan masyarakat. Malcolm Brownlee mengartikan etika menyangkut pemikiran yang sistematis tentang kelakuan, motivasi, dan keadaan batin yang mendasarinya. Dan definisi Malcolm inilah yang lebih tepat untuk definisi etika kristen, dimana Malcolm mengaitkan dengan sikap batin atau sikap hati yang mendasari perbuatan. Dimana sesuai dengan perkataan Yesus dalam kasus menghakmi perempuan berzinah (Mat. 5: 28), mereka belum melakukannya tapi hanya dalam hati mereka dianggap berdosa. ${ }^{3}$

\section{Kolegialitas}

Kamus Besar Bahasa Indonesia Kontemporer memberikan arti kata "kolegialitas" adalah kata benda yang berarti "rasa setia kawan terhadap teman sejawat". ${ }^{4}$ Ini berarti, sebagai pelayan harus menjalin suatu relasi yang baik antara satu dengan yang lain. Sehingga nantinya semua mampu menjadi Pelayan yang sehati, sepikir dan sepenanggungan. Pernyataan ini tentunya tidak membatasi kerjasama antara pendeta bersama penatua dan diaken atau pendeta emeritus serta mantan gembala yang mungkin menjadi jemaat. Menumbuhkan kolegialitas bukan hanya bertujuan untuk mempererat hubungan antarpendeta, tetapi juga dapat menjadi model kerjasama yang layak diteladani oleh seluruh pelayan bahkan jemaat secara luas.

\footnotetext{
2 Dr. Marlon Butarbutar, Bahan Ajar,..

3 Karel Sosipater,Etika Pelayanan,(Jakarta:Suara Harapan Bangsa,2010), 1-2

4 Peter Salim,..., 754
} 
Kolegialitas terkait erat dengan bentuk relasi yang dibangun antar kolega atau teman sejawat. Berbicara tentang kolegialitas pendeta, maka yang berelasi adalah pendeta dengan koleganya dalam melayani bersama. Jika dikaitkan dengan kepemimpinan, kolegialitas pendeta terkait dengan kepemimpinan tim (kepemimpinan yang melibatkan lebih dari satu orang). Kolegialitas juga merupakan wujud konkrit pertemanan dengan kolega. Tidak hanya itu, kolegialitas juga dapat terlihat dalam bentuk komunikasi yang dibangun antar teman sejawat. Kolegialitas tidak hanya dipahami secara sempit sebagai kepemimpinan tetapi sebaliknya memiliki makna yang lebih luas. Hubungan antar pendeta adalah sebuah tindakan teologis dan sekaligus tindakan etis. ${ }^{5}$ Kolegialitas pendeta bisa menjadi pusat inspirasi dalam kehidupan bergereja. Dengan demikian penulis memilih untuk memaknai kolegialitas "sebagai sebuah hubungan atau relasi antar teman sejawat yang saling terkait dan mempengaruhi dalam seluruh aspek kehidupan, baik yang bersifat pribadi maupun organisasi (bersama-sama)". Kolegialitas yang coba diangkat dalam tulisan ini adalah "kolegialitas pendeta". Dengan demikian pembahasan akan kolegialitas pendeta memfokuskan pada "hubungan antar pendeta" dalam menjalankan tugas panggilannya untuk melayani.

\section{BAB III}

\section{SIKAP ETIS HAMBA TUHAN TERHADAP KOLEGIALITAS DALAM PELAYANAN.}

\section{A. Latar belakang masalah.}

Kolegialitas sebenarnya berasal dari cerita di Alkitab melalui kisah Musa. Musa yang melayani Allah bersama-sama dengan rekan sekerjanya. Saat Musa diutus oleh Allah untuk memimpin Israel keluar dari tanah Mesir, ia tidak sendirian. Dalam kesadaran akan keterbatasannya, ia memerlukan orang lain untuk memperlengkapinya. Jika memperhatikan kisah di atas maka kolegialitas sejak dahulu juga sudah terjalin dalam menjalankan panggilan Tuhan. Jika sekarang kolegialitas menjadi kebutuhan sebenarnya bukan masalah baru. Justru malah semakin berkembang mengikut perkembangan zaman ini. ${ }^{6}$ Dalam perjanjian baru misalnya, paulus pernah mengalami hal yang sama. Dimana kolegalitasnya dalam melayani di pertentangkan oleh jemaat yang ada di Korintus. Pertentangan itu muncul saat jemaat mulai mengolong-golongkan diri dengan membeda-bedakan para pelayan yang pernahmelayani jemaat tersebut. Namun, paulus menyikapinya dengan sikap etis yang mengacu pada sikap etis kristen yang baik. Paulus menyatakan "Aku menanam, Apolos

\footnotetext{
5 http://theopreneurship-yahw.blogspot.co.id/2009/02/etika-profesi-pendeta-kolegialitas.

${ }^{6} \mathrm{http}: / /$ sinta.ukdw.ac.id/sinta/resources/sintasrv/getintro/51150010/77da0ed790e72033f29ff26 6ef8432fo/intro.pdf
} 
menyiram, tetapi Allah yang memberi pertumbuhan". perkataan mengandung suatu hikmat ilahi yang tertanam dalam pikiran Paulus, bahwa semua manusia sama di hadapan Allah. Paulus tidak memegahkan dirinya atau rekannya Apolos sebagai legenda gereja atau jemaat, meskipun mereka memang telah melakukan pekerjaan yang luar biasa. Karena itu harus juga disadari, bahwa pekerjaan yang luar biasa itu adalah karunia dari Allah semata. Hal ini jelas dinyatakan pada ayat 7 "Karena itu yang penting bukanlah yang menanam atau yang menyiram, melainkan Allah yang memberi pertumbuhan".

Dalam teks ini sangat jelas tertulis bahwa tidak ada sikap paulus yang sepertinya dia iri atau cemburu dengan koleganya, malahan dia memuji koleganya dengan apa yang sudah dilakukan pada jemaat di korintus. Disini sangat terlihat jelas sekali bahwa paulus sangat menyikapi dengan etis bahwa kolegialitas sangat dibutuhkan dalam melayani jemaat. Seharusnya sikap seperti inilah yang harus dimiliki setiap hamba Tuhan dimana perlu memandang bahwa kolega itu bukanlah lawan melainkan rekan sekerja yang dapat menolong jemaat untuk bertumbuh, karena tidak mungkin dalam waktu yang bersamaan semua jemaat terlayani dengan baik, perlu ada rekan perlu ada sikap yang mau menerima terhadap kolegialitas. Kong Fu Tze (551-479 SM) filsuf legendaris Tiongkok mengatakan: Saling bertemu dan menjadi kawan, adalah mudah; tetapi tetap bersatu dan hidup damai itulah yang sukar.7 Sukar, bukan berarti tidak bisa kita wujudkan melainkan harus kita upayakan terus-menerus. Mengupayakan kolegialitas pendeta dalam mengemban tugas pelayanan. Keharusan bekerja dalam tim sesungguhnya lebih penting bagi pendeta ketimbang para profesional yang lain. ${ }^{8}$ Pentingnya pendeta memahami posisinya sebagai bagian dari tim adalah bahwa publik yang dilayani oleh pendeta merupakan sebuah komunitas yang terstruktur berbeda dengan profesionalitas yang lain melayani masyarakat umum yang tidak selalu terhubung satu sama lainnya. ${ }^{9}$ Seorang pendeta harus dengan rendah hati memahami dan menyadari bahwa pelayanannya sebagai satu titik kecil saja dalam rangkaian pelayanan gereja yang telah terbentuk selama berabad-abad tahun lamanya dan masih akan terus berlanjut sampai ke generasi-generasi mendatang. Maka, seperti diyakini oleh Trull dan Carter, hubungan antar pendeta adalah sebuah tindakan teologis dan sekaligus tindakan etis. ${ }^{10}$ Seorang pendeta tidak hanya menguasai bagaimana berteologi namun juga bagaimana melakukannya. Bagaimana pendeta berteologi tentang hubungannya dengan kolega kalau dia sendiri sebenarnya tidak bisa membangun relasi

\footnotetext{
7 Karel Sosipater, Etika Pelayanan,. 177.

8 http://theopreneurship-yahw.blogspot.co.id/2009/02/etika-profesi-pendeta-kolegialitas.html

9 Ibid..,

10 Joe E. Trull and James E. Carter, Ministerial Ethics: Moral Formation for Church Leaders,(Grand Rapids: Baker Academics, 2004). 125
} 
dengan pendeta yang melayani dalam satu gereja yang sama apalagi dengan pendeta dalam aras Klasis maupun Sinode?

Membangun kolegialitas pendeta, berarti tidak melayani sendirian melainkan bekerjasama dengan koleganya. "Alone we can do so little, together we can do so much (Sendiri...hanya sedikit yang dapat kita lakukan, bersama... banyak yang dapat kita lakukan" (Helen Keller). ${ }^{11}$ Bukankah pekerjaan jika dilakukan lebih dari satu orang akan berbeda jika dikerjakan seorang diri saja? Seiring perkembangan zaman dengan tantangan dan kebutuhannya maka mengerjakan pekerjaan secara bersama-sama tidak lagi menjadi pilihan tetapi sudah menjadi kebutuhan. Sebagai anggota tubuh Kristus kita harus menyadari peran kita dan juga peran rekan sepelayanan lainnya. Dalam Alkitab dicatat adanya pelayanan yang kurang harmonis dalam kebersamaan karena ada motivasi yang kurang murni dalam melayani. Beberapa diantaranya adalah: ${ }^{12}$

- Jemaat Korintus yang senang membentuk kelompok-kelompok; kelompok Kefas/Petrus, kelompok Apolos, kelompok Paulus, kelompok Kristus, sehingga tidak ada kesatuan (1 Kor 1:10-17).

- Motivasi dari beberapa pemberita Injil yang justru bermaksud memperberat pemenjaraan Rasul Paulus. (Fil 1:17)

- Motivasi pelayanan untuk lebih menyenangkan hati manusia daripada hati Tuhan (Galatia 1:10)

\section{B. Sikap Etis Hamba Tuhan terhadap Kolegialitas pelayanan}

Jika hamba Tuhan menyadari, bahwa kita semua adalah saudara dan terhisap sebagai tubuh Kristus, maka kita tidak akan mempermasalahkan perbedaan tetapi akan menekankan kesamaannya, yaitu sama-sama melayani Tuhan, menyampaikan Firman yang sama berdasarkan Alkitab, dan Yesus Kristus satu-satunya penyelamat dan kepala Gereja sehingga muncul sikap saling menghormati diantara sesama pelayan dalam mengembangkan jemaat. Pdt. DR. Karel Sosipater menuliskan beberapa sikap etis yang harus dilakukan seorang hamab Tuhan terhadap kolegialitasnya dalam pelayanan, diantaranya; ${ }^{13}$

\section{Saling menghormati dan saling menghargai.}

Para Pelayan sudah seharusnya saling menghargai dan menghormati dan tidak menganggap dirinya lebih tinggi dari yang lain sekalipun dia pemimpin jemaat. (Rom. 12:10) Bila kesadaran ini yang terjadi, maka akan timbul rasa persaudaraannya sebagai sesama

\footnotetext{
11 Robby I. Chandra, Kamu Juga Bisa Meraih (Cara meraih mitra dan menghasilkan kerjasama),(Jakarta, Young Leaders Indonesia, 2011) . 47

12 Dr. Marlon Butarbutar, Bahan Ajar,..

13 Karel Sosipater,...., 176-184
} 
anak Allah dan sesama HambaNya yang melayani dan sesama mengabdi kepada Tuhan dalam melebarkan kerajaan-Nya di dunia.

\section{Membina hubungan dan persekutuan.}

Sikap ini menciptakan keharmonisan diantara sesama pelayan Tuhan, apalagi di Gereja yang sama atau berjemaat di dalam Gereja yang dulu pernah digembalakan (Fil. 1:27). Persekutuan untuk bekerja sama dalam meningkatkan pelayanan mengasihi sesama, seperti; mendoakan jemaat, mengunjungi jemaat, dan memberikan dukungan moril bagi jemaat. Selain itu juga persekutuan menghindari kesalahpahaman atau persoalan kecil tidak membesar tetapi dapat diselesaikan.

\section{Tidak mengkritik atau menghakimi.}

Adalah sikap yang kurang baik, jika pendeta gemar mengkritik sesama hamba Tuhan (Yoh. 8:15; Yak. 2:4). Juga sikap tidak etis, bila ada hamba Tuhan yang membuat suatu penghakiman kristis, terhadap hamba Tuhan lain dengan menyebut namanya, yang masalahnya sendiri belum tentu kebenarannya (Rom. 14:13). John williams dengan tegas mengatakan, ketika hamba Tuhan mengkritik atau menghakimi hamba Tuhan yang lain, maka dia sedang mengutuki dirinya sendiri. Ada baiknya jika memberikan kritikan melalui nasehat dengan mendatangi hamba Tuhan tersebut sebgai wujud dari sikap perhatian dan kasih. (Titus 1:9)

\section{Tidak iri, memusuhi dan menyebarkan gosip yang tidak baik.}

Hamba Tuhan harus menyadari bahwa tugas mereka adalah sebagai pedamai (I Timotius 3:3) bukan perusak, maka jangan jadi hamba Tuhan yang suka berselisih atau bertengkar dan iri hati dengan sasama pelayan Tuhan (Gal. 5:20). Menyebarkan gosip tentang sesuatu hal terhadap hamba Tuhan lain itu tidak jauh berebeda dengan memfitnah (I Pet. 2:1). Sebab apa yang digosipkan itu sendiri belum tentu benar, tetapi motivasi sebenarnya adalah bertujuan untuk menjelekkan aatu menjatuhkan nama baik hamab Tuhan lain (II Tim. 2: 23). Seharusnya berfikir bagaimana menjadi hamba Tuhan yang menjadi berkat bagi hama Tuhan lain.

\section{Tidak berebutan pelayanan}

Tidak berebutan disini maksudnya adalah, gembala yang aktif itulah yang seharusnya melayani jemaat yang ada di gerejanya, namun jika ada mantan gembala atau hamba Tuhan yang kebetulan ada di daerah gereja tersebut dan mau melayani mantan jemaatnya yang ada di gereja tersebut tanpa sepengetahuan gembala maka ini disebut tidak etis seolah berebut pelayanan (1 Tim 6: 5), maka ketika gembala tersebut mengetahui masalah tersebut alangkah idealnya dan terpujinya jika gembala yang akif tersebut mendatangi hamba Tuhan 
tersebut dan menawarkan untuk masuk dalam team pelayanan di dalam gereja. Dan masih banyak lagi sikap yang etis dala hubungan pelayan dengan kolegialitasnya sesama hamba Tuhan guna untuk kemuliaan nama Tuhan. 


\section{BAB IV}

\section{KESIMPULAN.}

Sebagai kesimpulan dari makalah ini kolegialitas Hamba Tuhan ya sesama hamba Tuhan. Jika terjalin kerjasama yang baik maka tidak ada lagi mantan pelayan atau mantan gembala dalam satu organisasi Gereja, seharunya membangun kerjasama untuk menumbuhkan iman jemaat. Sikap etis terhadap kolegialitas di kalangan hamba Tuhan merupakan rekan sekerja Allah, Oleh sebab itu kita harus memiliki sikap yang baik dan benar terhadap rekan sepelayanan, dimana perlu menghargai sesama rekan sepelayanan, apapun profesinya dan apapun bentuk pelayanannya, bahkan yang satu menganggap yang lain lebih utama (Fil 2:1-4). Mempunyai sikap saling membutuhkan baik dalam saling tukar menukar informasi, saling mendoakan, saling menolong dan memberi penghiburan (Gal 6:2). Mau bersikap terbuka tanpa takut terluka dalam menyelesaikan masalah yang timbul dalam pelayanan; bersedia mengakui kesalahan dan meminta maaf, dan juga bersedia mengampuni mereka yang bersalah. Bersikap mau menegur dalam kasih apabila melihat atau mendengar ada rekan sepelayanan yang menyimpang dari kebenaran Firman Tuhan (Amsal 28:23) 